\title{
Research on Spreading of Old Ancient Dance Aerobics
}

\author{
Ailuan Huang \\ Hainan Tropical Ocean University, Sanya, 572000, China
}

\begin{abstract}
Old ancient dance aerobics is an exercise project which is simple to learn, rich in content and suitable for different groups of people. It can inherit and carry forward traditional culture of li nation, promote village culture construction of li nation, boost physical and emotional health of Hainan people, advance tourism industry development of Hainan and improve national fitness development for all. We suggest the spreading of old ancient dance aerobics in schools and colleges, urban and rural communities, scenic areas and internet and media.

Keywords: old ancient dance aerobics, fitness value, spreading value
\end{abstract}

Old ancient dance is one of the original ecology traditional activities of Li nation. It originated in religious ceremonies, which is a folk activity Li ancestors worship ancestors. The old ancient dance has close relationship with the people's production and life, customs and religious beliefs. It has been listed as the third batch of national intangible cultural heritage. However, with the changes of the times and the modern western culture impact, the ancient dance of the original ecology folk activities declined, is facing the disappearing situation. In order to make the ancient dance activities to the development of the times, meet the people's diverse fitness needs and further promote the development of sports for all. According to the principles and methods of national aerobics in China, we combine the old dance elements and the modern fashionable aerobics basic movements together, creating the "old ancient dance aerobics". 


\section{Features of old ancient dance aerobics}

\subsection{Strong rhythm}

Old ancient dance aerobics music is mainly extracted from the original ecology of the ancient music and dance movement, strong aerobics rhythm and the combination of creation, melodious music melody, fashionable and distinctive rhythm, can give practitioners a youthful vitality and dynamism.

\subsection{High artistry}

Aerobics is a pursuit of health and beauty of sports. It is the broad masses of the people to pursue the highest level of physical health and beauty. The content of action is artistic beauty, beauty of form, emotion and artistic conception. It is a kind of living art. The ancient dance aerobics has the artistic characteristics of aerobics, and ancient dance art. By participating in the ancient dance aerobics exercise, can enjoy the beauty in improving their aesthetic consciousness and artistic accomplishment.

\subsection{Extensive applicability}

Old ancient dance aerobics can help people to keep fit, which is in line with the modern pursuit of psychological needs. Its action is easy to learn and practice in various forms, rich in content, not a specific limitation of the site does not require special equipment, practice is simple and safe, suitable for different industries, different age, different gender and different physical crowd participation.

\subsection{Rich nationality}

Old ancient dance aerobics is the main characteristics and basic law of extraction in ancient dancing posture, basic steps and representative action and aerobics combination of basic movements and the creation, has the rich cultural connotation of $\mathrm{Li}$, through practice allows participants to enjoy the unique style and the understanding of the history of Li culture.

\section{Analysis of Spreading Old Ancient Dance Aerobics}

\subsection{Inherit and carry forward traditional culture of Li nation}

Old $\mathrm{Li}$ people dance is created in the long process of production and labor, and $\mathrm{Li}$ people's life and production is closely related to the content structure and form is the representation of the ancient $\mathrm{Li}$ people's living environment and the labor scene, is a special kind of reflect the cultural life of the Li people at that time. Although the ancient dance and aerobics combined with creation became the "old dance aerobics", but it still retains the cultural connotation and characteristics of the original ecology of the action of li. It is not only different from modern competitive sports, but also not a universal form of sports. But it can vividly 
reflect the people's life and history. Therefore, popularizing the ancient dance aerobics sport, people can feel the history and culture, promote national understanding between the identity of Li culture to inherit and carry forward the traditional culture.

\subsection{Promote village culture construction of $\mathrm{Li}$ nation}

In recent years, the government has done a lot of job to promote the development of rural people's physical and mental health and enrich and activate their cultural life. Ancient dance aerobics contains a strong flavor of $\mathrm{Li}$. It can eliminate the estrangement of Li village people due to life style, different ideas and bring. The spread of the ancient dance aerobics can not only for the $\mathrm{Li}$ village people provide their production and life style appropriate characteristics of the project, but also can improve the rural sports resources, which plays a positive role in promoting the construction of village culture.

\subsection{Boost physical and emotional health of Hainan people}

Old ancient dance aerobics is an easy and beautiful aerobic exercise, it can promote the healthy body, muscle, bone, joint symmetry and harmonious development in the strong rhythm of the music accompaniment, with passionate emotion and energetic movement, strong modern, so that people in the course of practice is easy to stimulate emotion and spirit, can effectively stimulate the learner's initiative and enthusiasm, so that practitioners forget fatigue, worry and social work pressure, get unlimited enjoyment of beauty, have a pleasant emotional experience from the heart, actively participate in the exercise. At the same time, people in the old ancient dance aerobics, both rich the social life, and mutual emotional communication, mutual understanding and trust, to cultivate the national spirit of solidarity and cooperation consciousness, promote the harmonious interpersonal relationship, individual and community, community and society and healthy development, so as to improve the A high degree of civilization of the whole society. Therefore, ancient dance aerobics is national sports is very useful to a study of Hainan province people's physical and mental health, emotional communication.

\subsection{Advance tourism industry development of Hainan}

In the construction of international tourism island, the development of ancient dance aerobics, to enrich the cultural connotation of the international tourism island, has important significance to enhance the attractiveness of tourism. The past cursory style sightseeing, has been unable to meet the needs of the tourism market, the diversification of tourism will gradually prevail. More and more people like the relaxed and lively, rich and colorful, in the tour in music, play a combination of tourism. In recent years, travel agencies, travel companies, especially in ethnic areas, in order to meet the needs of the tourism market, attract more tourists and have launched a number of distinctive folk custom tourism projects. If the tourists can watch folk dance performances, and participate in a 
fancy dance aerobics, will enable visitors to physical and mental pleasure and eliminate fatigue, relax the spirit, to adjust the objective spirit to continue active travel, to provide some help for the development of the tourism industry. Thus, ancient dance aerobics can expand the tourism space, and can promote the tourism industry of Hainan province is converted from quantity to quality.

\subsection{Improve national fitness development for all}

Ancient dance aerobics has wide adaptability, suitable for different physical and mental characteristics, social life level, social and cultural needs of the people, it is not that competitive sports confrontational fierce, unlike that of national dance practice action requirements so high, and its movement combination movement routes are relatively simple, but full of each joint the physical activity. Different gender and age people according to their physical condition voluntarily choose to participate in ancient dance aerobics. Therefore, ancient dance aerobics is a physiological and psychological characteristic of people, and having sports fitness. Effects of the extensive development of ancient dance aerobics can improve people's fitness consciousness, expand the mass sports exercise team, physical exercise increases the total population, which plays a strong role in the implementation of the national fitness program.

\section{Concrete measures of spreading old ancient dance aerobics}

\subsection{Spread in schools and colleges}

The promotion of old ancient dance aerobics in the campus of colleges and schools should followed the following directions. First, teachers learn ancient dance aerobics skills and theoretical knowledge and enhance teachers' old dance aerobics teaching level. Second, introduce the ancient dance aerobics campus into the teaching syllabus, establishing diversified old dance aerobics curriculum system; and the creation of the ancient dance aerobics elective course. Third, set up in the old campus dance aerobics clubs, associations and clubs, held regularly in ancient dance aerobics training, performances, competitions, and constantly improve the old dance aerobics in campus influence. Fourth, to make full use of campus radio, blackboard, window and billboards and other publicity carrier, strengthen the old dance aerobics movement, exercise method, value and development of regular and non-regular exhibitions, publicity.

\subsection{Spread in urban and rural communities}

We can start from the provincial government led by the old dance aerobics class, cultivate old dance aerobics students, and the establishment of ancient dance aerobics learning and research team, in the premise of systematic organization, we can carry out a wide range of ancient dance fitness exercises of this project in various towns, communities, first of all we to strengthen the old dance aerobics in the urban and rural community, improve people's awareness of the ancient dance 
aerobics, Sports Association and sports culture rely on grass-roots organization and advocate the strength to stand. Secondly, the backbone of the training of ancient dance aerobics project, play an important role in social sports instructors work, let the backbone to widely promote the ancient dance aerobics. Through a series of supporting measures, the ancient dance aerobics in Hainan in various urban and rural communities. This is for the development of the national fitness campaign to inject new blood and vitality, also can make the ancient dance aerobics is more people know and accept and participate, so as to achieve the promotion and popularization of aerobics dance in ancient culture, the ancient dance aerobics culture to maintain vitality.

\subsection{Spread in scenic areas}

With the people's living standards and health awareness continues to increase, tourism products from sightseeing to leisure, sports and other aspects of the development of sports tourism products has become the main product of China's tourism market. In order to better tourist attractions widely in ancient dance aerobics, first of all, regional tourism management leadership to plan for ancient dance aerobics into tourist attractions to do a detailed plan. A number of local attractions such as training ancient dance fitness project personnel performing aerobics dance and old coach, and then through the performance and entertainment to promote the ancient dance aerobics in the tourist area, not only for tourists to participate in this personally on the scene of cross-cultural communication experience, so that visitors have a profound understanding of the culture of Hainan. It also strengthens the unity of all ethnic groups, the more conducive to cultural heritage.

\subsection{Spread in internet and media}

With the help of this positive social function of network media, the old ancient dance aerobics on the network can promote the dissemination, or made into a sports column on the sports channel in regularly broadcast propaganda, its origin and development, explanation and demonstration of "ancient dance aerobics" into action; let people in the busy modern life in the homes will be able to understand and learn the ancient dance aerobics, so that people can adjust the body and mind, the release of pressure, physical exercise in a relaxed and harmonious atmosphere.

\section{Conclusion}

Old ancient dance aerobics is the culture and art of the Chinese nation a bright pearl in the treasure house, is the epitome of the development of $\mathrm{Li}$ people's social and cultural and artistic performance. It is close to people's production and life, with distinct characteristics of the times, there is a double effect of physical fitness, mental health. It is not only beneficial to the reform of school physical education and the diversification of community sports, but also to enrich the social and cultural life of the people of Hainan. The promotion of ancient dance 
aerobics can make physical education and community sports in minority areas blaze a new path with Chinese characteristics.

\section{Acknowledgement}

The research work was supported by the Foundation of Philosophy and Social Sciences Project of Hainan Province in 2016 (Grant No. HNSK (QN) 16-118) and the Foundation of "13th Five Year Plan" Project of EducationalScience in Hainan Province (Grant No. QJY13516025).

\section{References}

[1] Han Chunying, Characteristics and Function of Body Building Exercise of Xinjiang Ethnic Dance, Journal of Xinjiang Vocational University, 22(6), pp. $52-$ $53+80,2014$.

[2]XuAimei, On the value and prospect of national body mechanics, Journal of Physical Education, 14(8), pp. 64-67, 2007.

[3]BaiLuxia, Exploration of Influence of Aerobics on College Students'Body Self Concept in College Teaching, Bulletin of Sport Science \& Technology, 23(5), pp. 97-99, 2015.

[4]Guo Yi, Study on the Relationship Between Rumba and Chacha from the Analysis of Body Mechanics, Journal of Shanxi Datong University(Natural Science), 30(6), pp. 82-84, 2014.

[5] Yang Hong, The Choreography of Blood Pressure Controlling Body Exercise and Key Techniques, Journal of Chengdu Sport University, 37(3), pp. 63-65, 2011. 